\title{
Pressure-Enhanced Solid Phase Epitaxy: Implications for Point Defect Mechanisms
}

\section{Citation}

Lu, Guo-Quan, Eric Nygren, and Michael J. Aziz. 1992. Pressure-Enhanced solid phase epitaxy: Implications for point defect mechanisms. Materials Research Society Symposia Proceedings 205: 33-38.

\section{Published Version}

http://www.mrs.org/s_mrs/sec.asp?CID=1727\&DID=38980

\section{Permanent link}

http://nrs.harvard.edu/urn-3:HUL.InstRepos:2859903

\section{Terms of Use}

This article was downloaded from Harvard University's DASH repository, and is made available under the terms and conditions applicable to Other Posted Material, as set forth at http:// nrs.harvard.edu/urn-3:HUL.InstRepos:dash.current.terms-of-use\#LAA

\section{Share Your Story}

The Harvard community has made this article openly available.

Please share how this access benefits you. Submit a story.

\section{Accessibility}




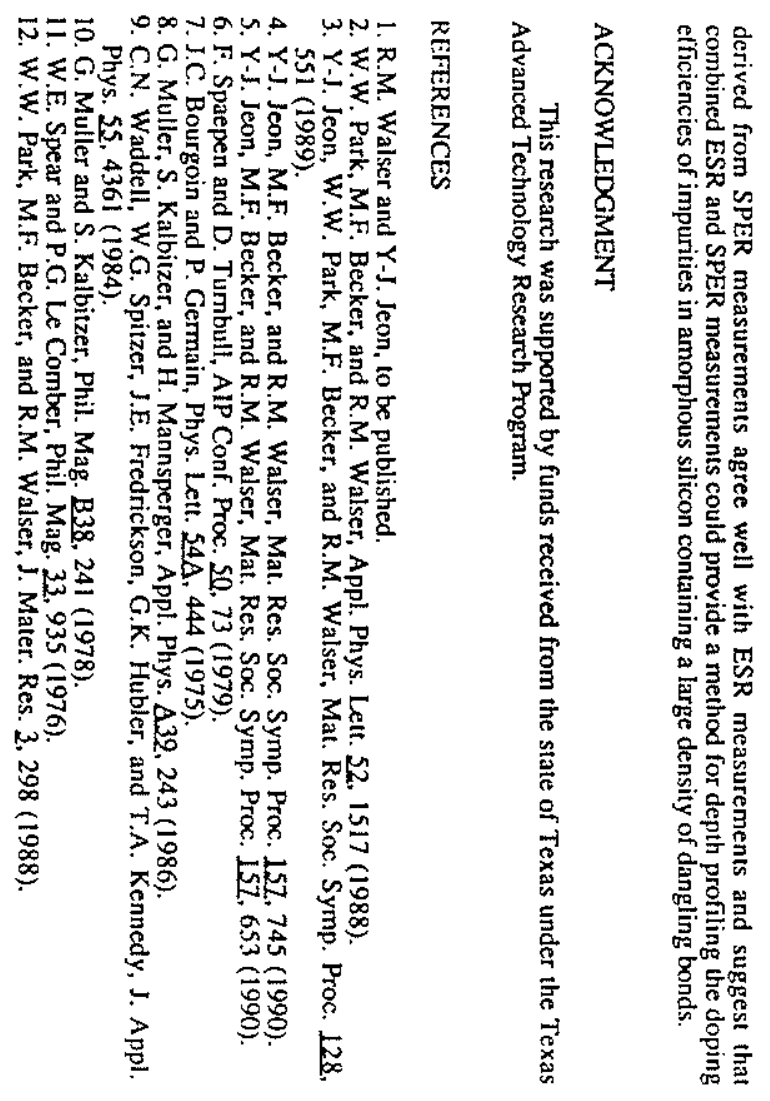
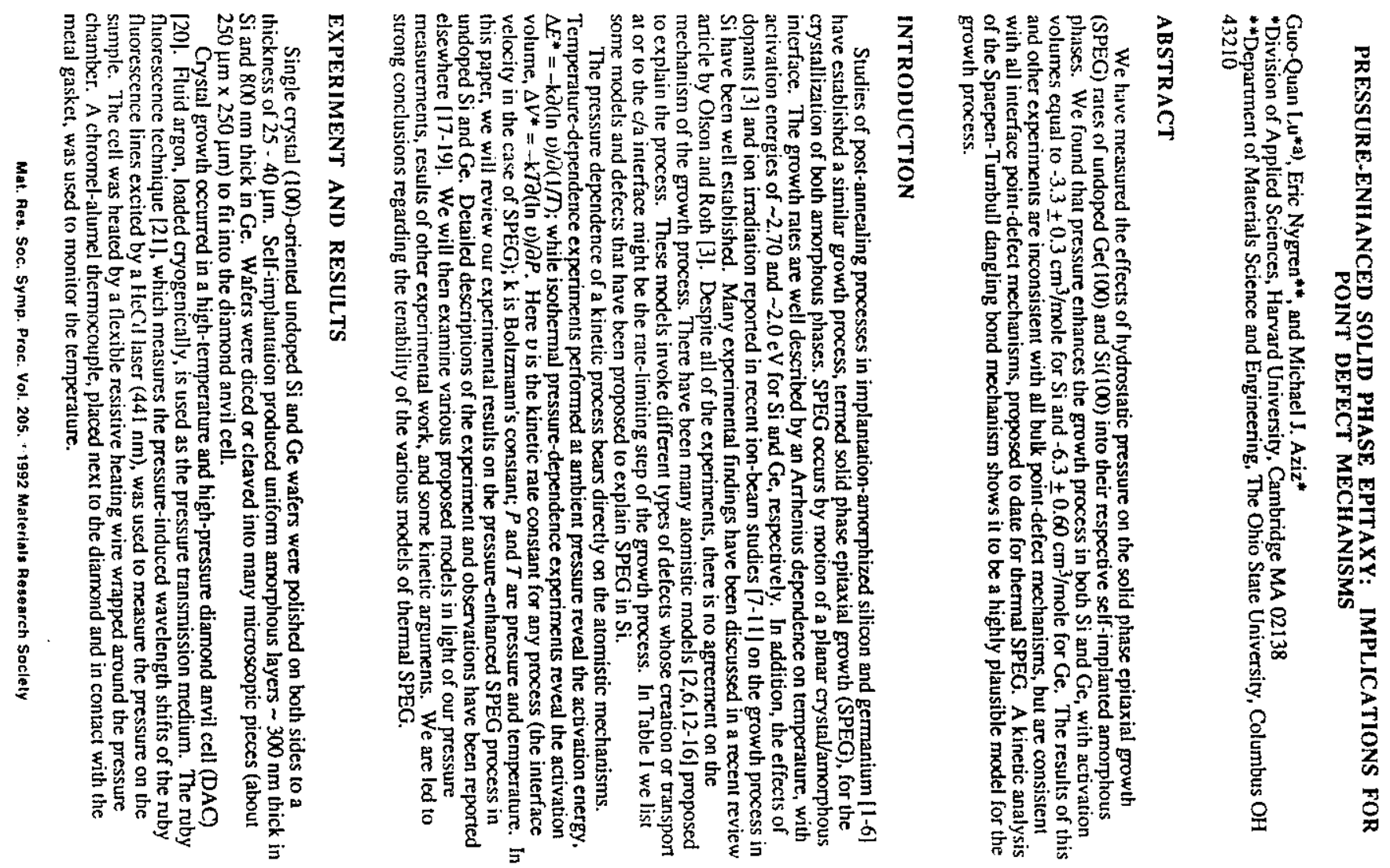


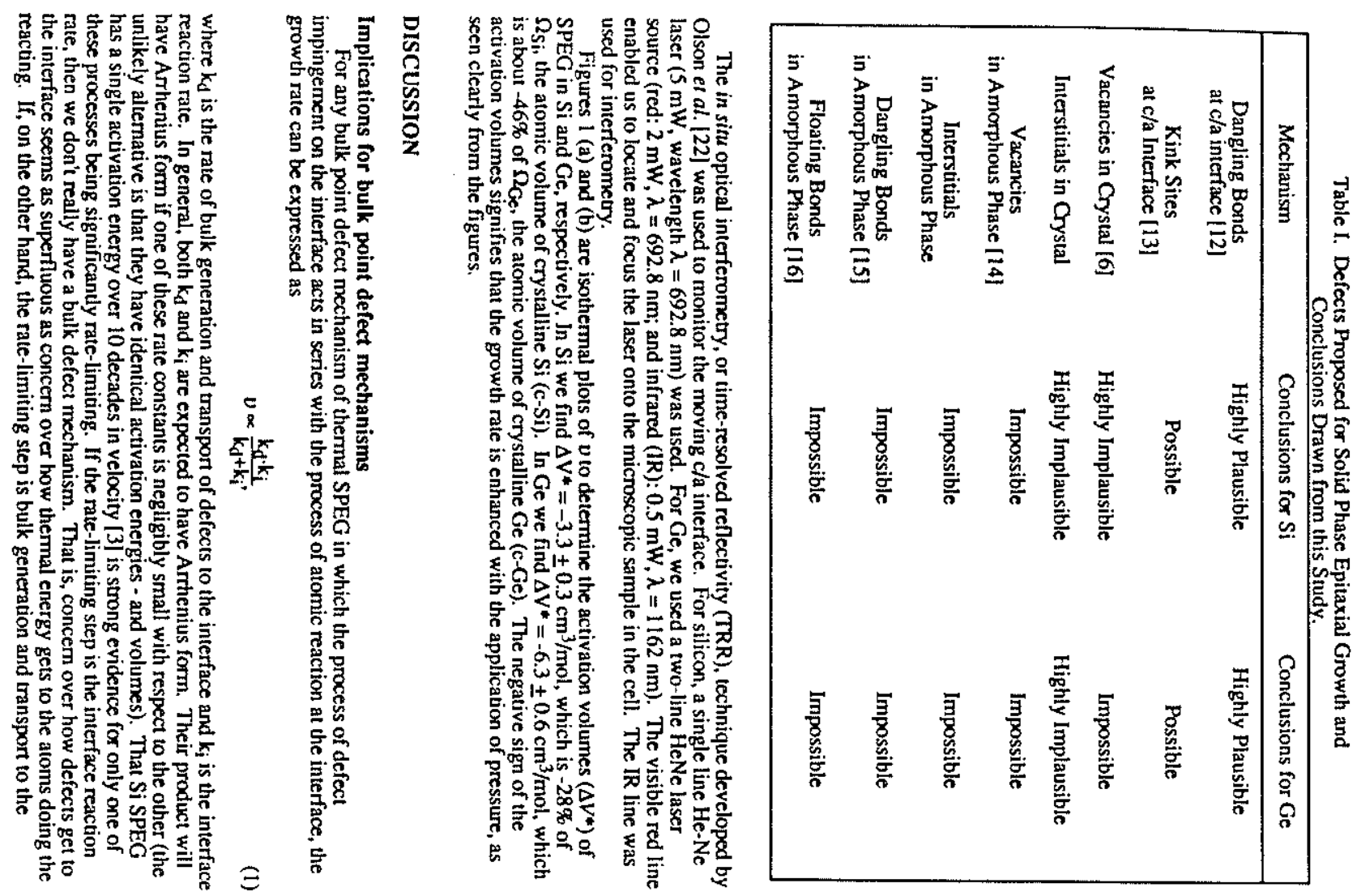

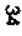
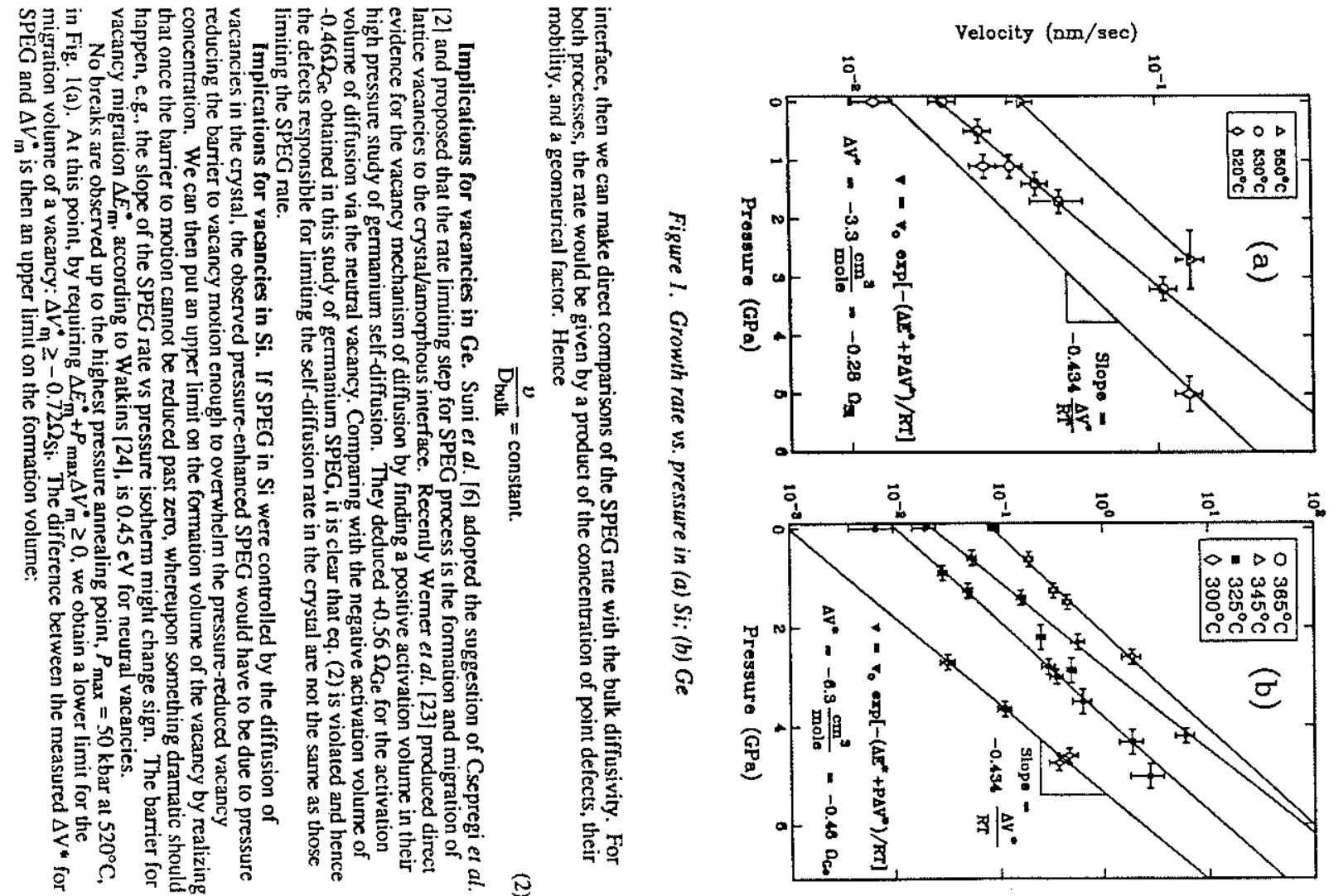

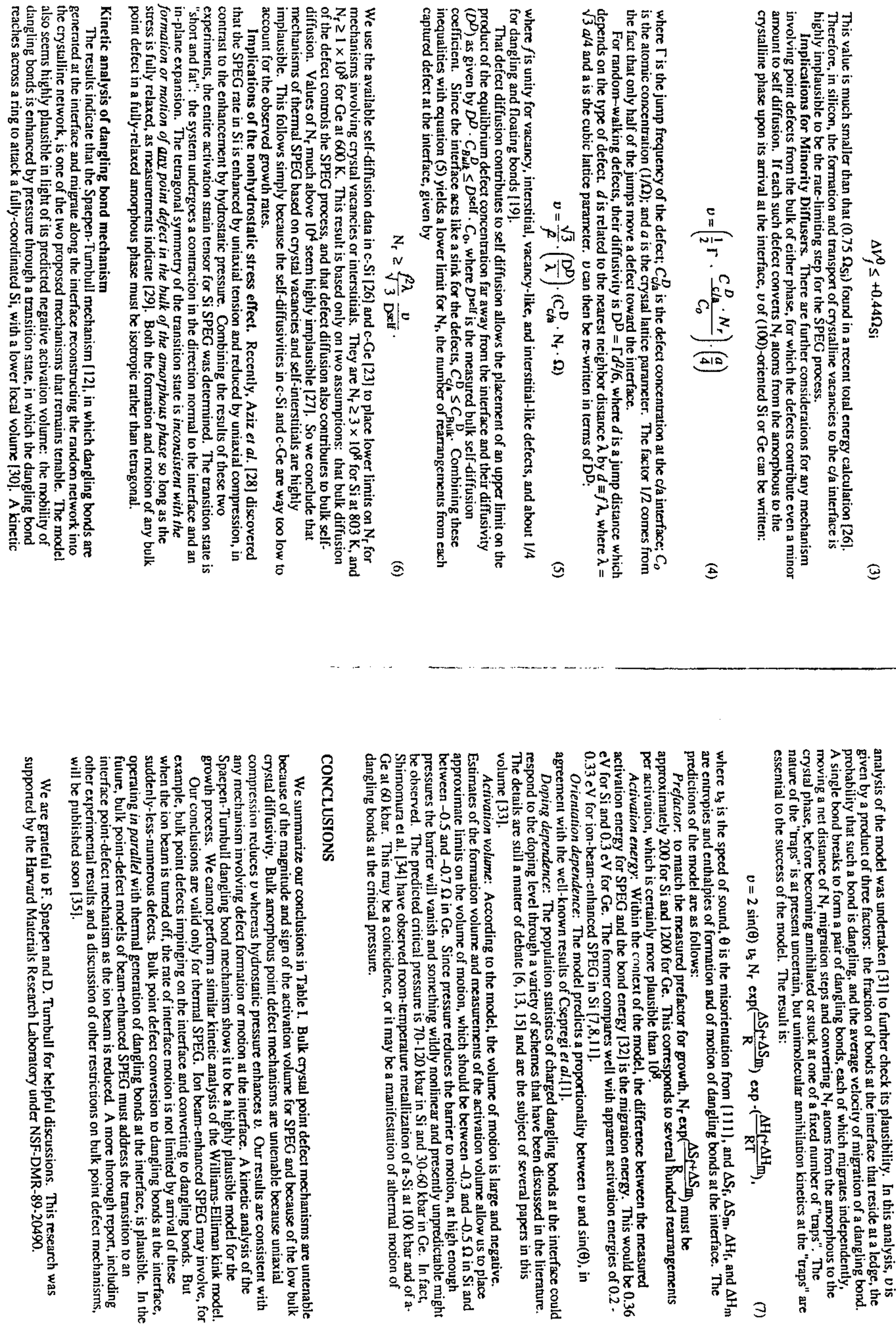

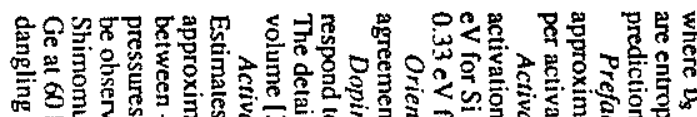

ơ

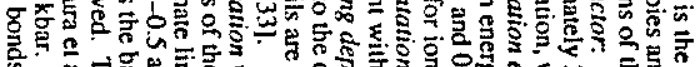

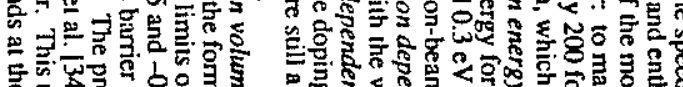

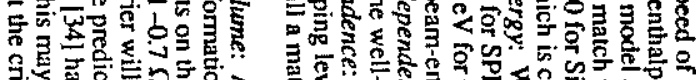

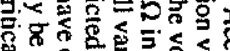

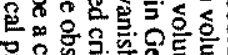

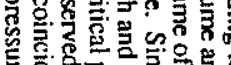

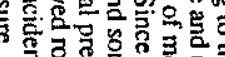

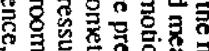

을

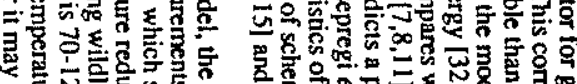

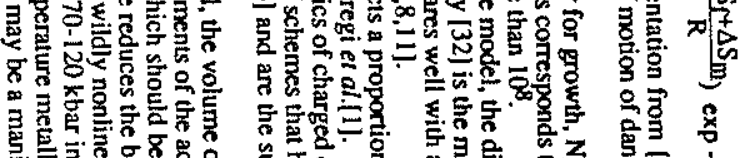

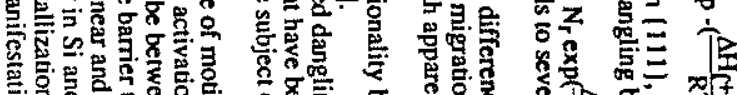

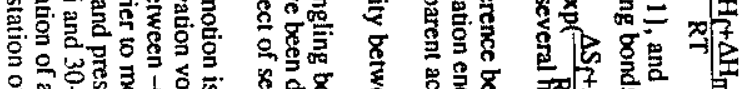

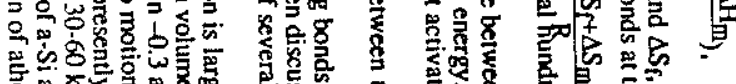

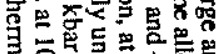

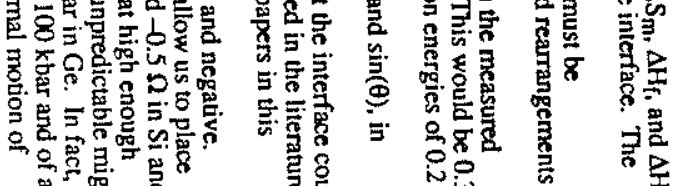

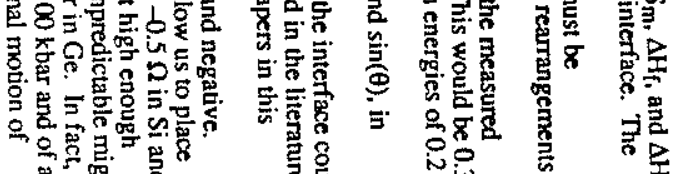

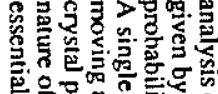

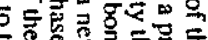

年

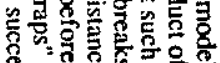

政

政

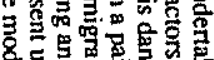

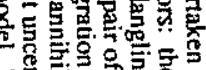

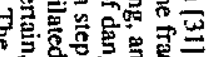

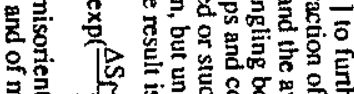

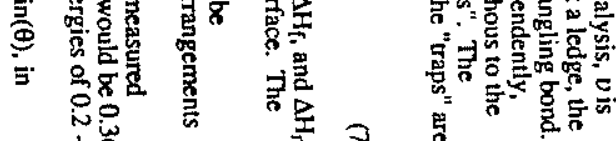

过 


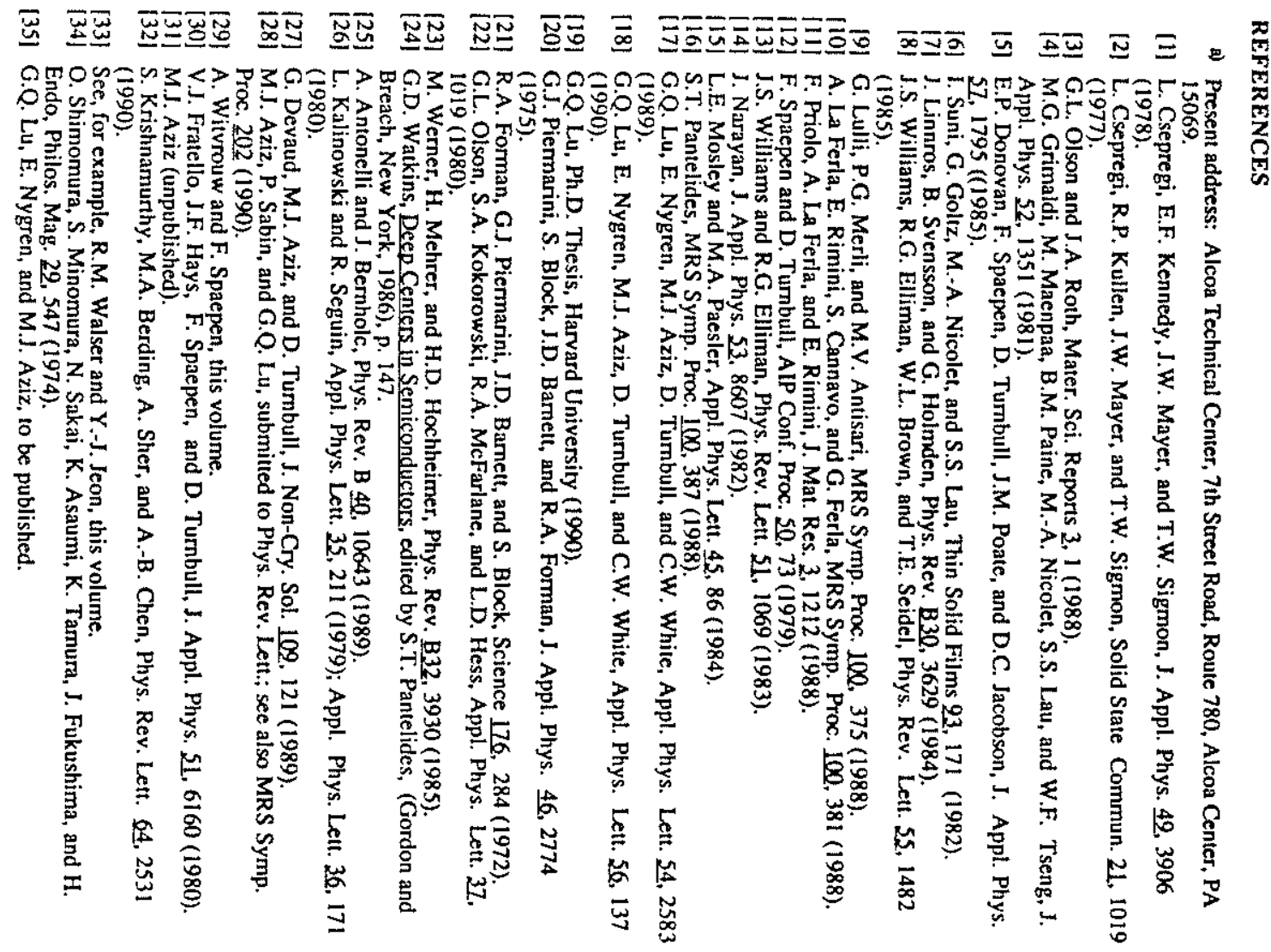

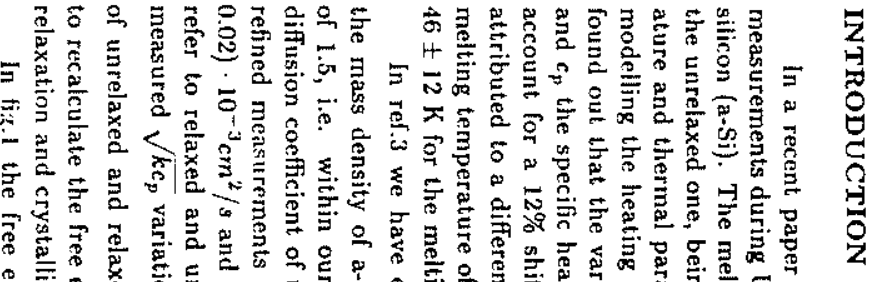

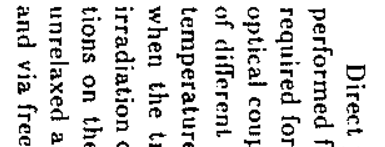

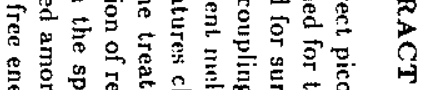

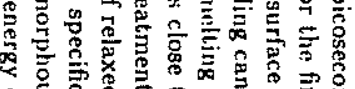

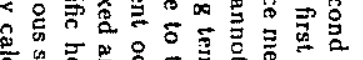

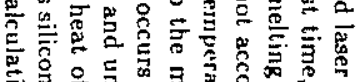

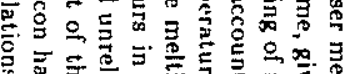

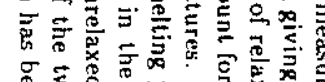

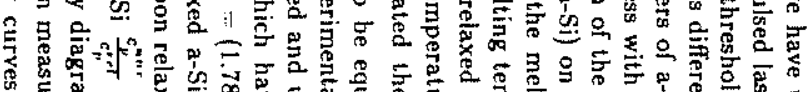

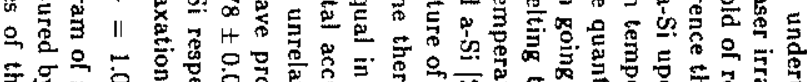

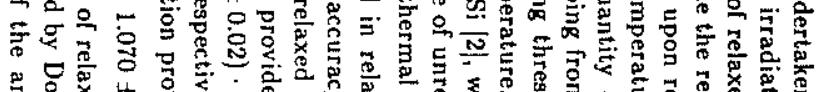

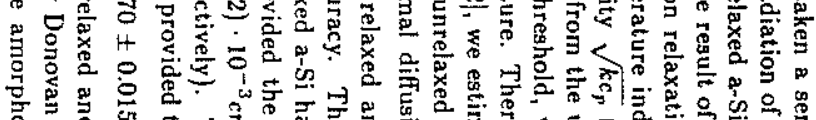

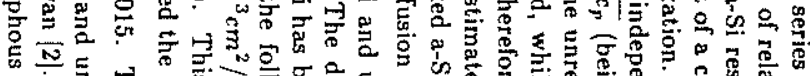

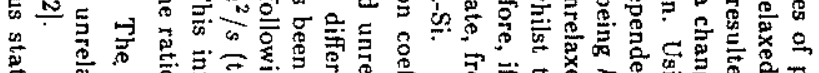

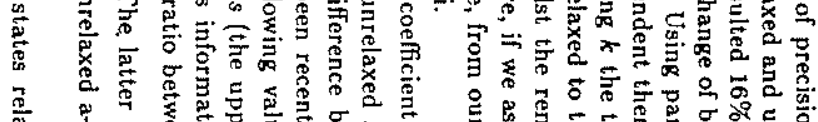

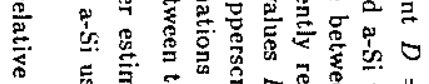

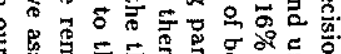

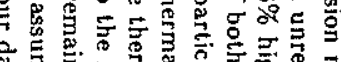

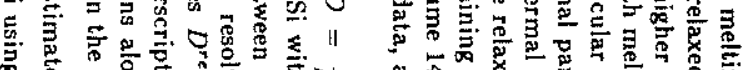

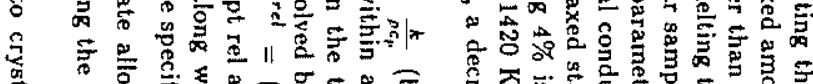

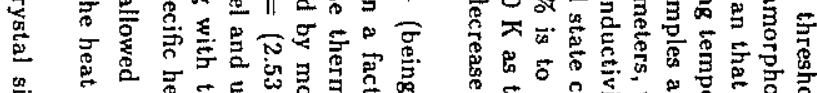

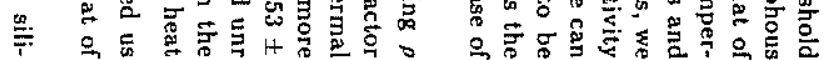

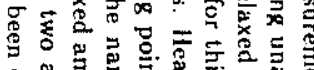

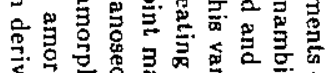

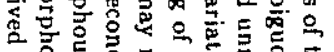

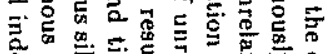

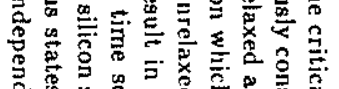

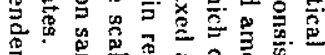

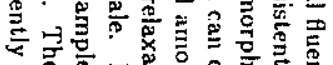

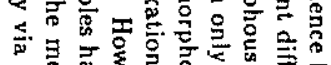

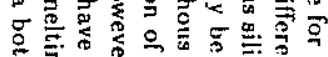

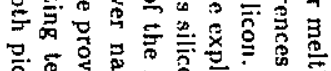

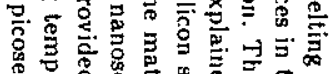

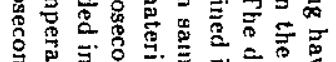

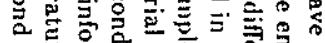

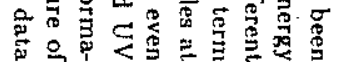

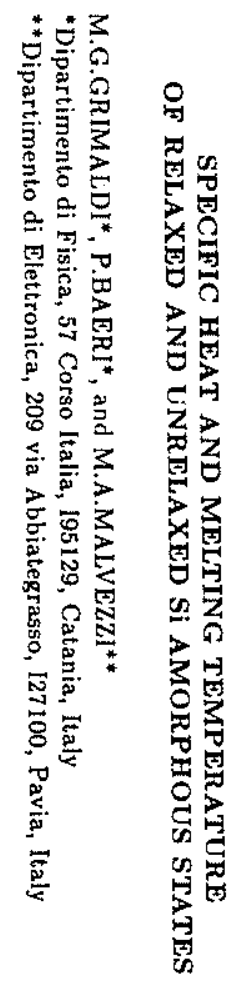

